\title{
Load Frequency Control of a Two Area-Power System with Non-reheat Turbines by SMC Approach
}

\author{
Jianping Guo \\ Department of Electrical Engineering, Cleveland State University, Cleveland 44114, USA
}

Received: February 12, 2015 / Accepted: April 03, 2015 / Published: June 30, 2015.

\begin{abstract}
Load frequency is an important issue in power system operation and control. In this paper, load frequency control for suppression frequency deviation in an interconnected power system with nonlinearities using SMC (sliding mode control) is studied. The governor dead band and GRC (generation rate constraint) is considered in this article. Digit simulations for both two areas and three areas power system with non-reheat turbines are provided to validate the effectiveness of the proposed scheme. The results show that, the robustness of the control method under parameters variation and different load disturbances with the SMC technique.
\end{abstract}

Key words: Sliding mode control, load frequency control, nonlinearities, robustness.

\section{Appendix A}

The nominal system parameters

$\begin{array}{ll}\text { Governor time constant } & T_{g i}=0.08 \mathrm{~s} \\ \text { Turbine time constant } & T_{t i}=0.3 \mathrm{~s} \\ \text { Power system time-constant } & T_{P i}=20 \mathrm{~s} \\ \text { Power system gain constant } & K_{p i}=120 \mathrm{~Hz} / \mathrm{p} . \mathrm{u} . \mathrm{MW} \\ \text { Droop coefficient } & R_{i}=2.4 \mathrm{~Hz} / \mathrm{p} . \mathrm{u} . \mathrm{MW} \\ \text { Frequency response coefficient } & B_{i}=0.425 \\ \text { Tie-line coefficient } & T_{i j}=0.545 \mathrm{p} . \mathrm{u} . \mathrm{MW} / \mathrm{rad} \\ \text { Governor dead band } & \pm 0.036 \mathrm{~Hz} \\ \text { Generation rate constraint } & 3 \% \text { p.u. MW } / \mathrm{min}\end{array}$

Note: The letter $i$ represents the number of an area: $i, j=1,2,3$, and $i \neq j$.

\section{Introduction}

The frequency of power system is an important factor to power system. Large frequency deviation can damage equipment, degrade load performance, cause the transmission line overloaded, interfere with the system protection schemes, and ultimately will lead to power system unstable. To solve this problem, load frequency is introduced which is used to drag the frequency to normal values under disturbance. Many

Corresponding author: Jianping Guo, doctoral candidate, research fields: power system and control system. E-mail: j.p.guo@vikes.csuohio.edu. control methods have been introduced to solve this problem. These methods include PI (proportional integral) control method, robust control, fuzzy logic control algorithm, neural network control, model predictive control and optimal control. PI control has the benefit of simple controller structure, but it can produce a long settling time and a large overshoot in transient response [1]. In order to identify the parameter uncertainties, advanced control methods have been developed. Advanced control methods include robust control method [2], fuzzy logic control method [3], fuzzy logic based PI controller [4, 5], model predictive control [6-9] and optimal control [10-13]. Sliding mode control methods [14-17] also have been applied to load frequency control. Before sliding mode control, either apply to the linear power system or the method is based on discrete control method. This paper deals with the nonlinear power system by continuous sliding mode control method.

This work proposes sliding mode control method for two areas interconnected power system with nonlinearities. Its performance is evaluated based on load disturbance change and parameters variation. Both areas of load frequency control are composed of non-reheat turbines. Also, the two areas of 
interconnected power system is based on nonlinear model which contains dead band and generation rate constraint.

This paper is organized as follows: the two areas nonlinear model of power system is given in Section 2; the sliding mode control is introduced in Section 3; the control solution is demonstrated in Section 4; the simulation results are shown in Section 5; finally, concluding remarks is summarized in Section 6.

\section{Nonlinear Power System Model}

The block diagram of two areas power system with nonlinearities is shown in Fig. 1. In Fig. 1, there are two areas interconnected power system with non-reheat turbines. Both areas contain the governor dead band and generation rate constraint. The transfer function for the governor is given in Eq. (1), where $T_{G i}$ is governor time-constant.

$$
G_{H}(s)=\frac{1}{1+s T_{G i}}
$$

The transfer function for the turbine is given by Eq. (2), where $T_{t i}$ is turbine time-constant.

$$
G_{T}(s)=\frac{1}{1+s T_{t i}}
$$

The transfer function for the power system is shown in Eq. (3), where $K_{P i}$ is power system gain constant and $T_{P i}$ is power system time-constant.

$$
G_{P}(s)=\frac{K_{P i}}{1+s T_{P i}}
$$

The governor dead band is set to $\pm 0.036 \mathrm{~Hz}$ according to NERC (North American Electric Reliability Corporation) rule [18, 19].

In the power system with steam turbines, power generation can change in a specific range. Normally, the value of generation rate constraint is $3 \%$ p.u. MW/min for the non-reheat turbine [18], which is equal to:

$$
\left|P_{G K}(t)\right| \leq 0.005 \text { p.u.MW/s }
$$

So two limiters, which is bounded by \pm 0.0005 are used in the power system with non-reheat turbine to prevent the excess control.

$$
\begin{gathered}
\Delta P_{t i e}=\frac{T_{i j}}{S}\left(\Delta f_{i}-\Delta f_{j}\right) \\
A C E_{i}=B_{i} \Delta f_{i}+\Delta P_{t i e}
\end{gathered}
$$

In a multi-area power system, in addition to driving the frequency error to zero. The tie-line power change should be maintained at scheduled values. The ACE (area control error) is linearly combination of frequency error and tie line power error. The tie line power error and area control error is defined as in Eqs. (5) and (6).

In Fig. $1, \Delta P_{g i}$ is the governor output change in area $i ; \Delta P_{m i}$ is the turbine output change in area $i$; $\Delta P_{L i}$ is the load disturbance in area $i ; \Delta f_{i}$ is the frequency error in area $i ; \Delta P_{\text {tiei }}$ is the tie-line power change between $i$ and other regions; $A C E_{i}$ is the area control error in area $i ; u_{i}$ is the control input; $B_{i}$ is the frequency response coefficient of area $i$; $R_{i}$ is the speed droop coefficient of area $i ; T_{i j}$ is the tie-line coefficient with area $j$.

\section{Sliding Mode Control}

Sliding mode control is a kind of robust control method. The major advantage of sliding mode control is that, it is insensitivity to the plant parameter variations and disturbance. Sliding mode control is capable of decoupling high order system into low order system, which reduces the complexity of feedback design. Also, sliding mode control is suitable for nonlinear, high order, and complex system. Sliding mode control has been proved to applicable in large scope of problems, such as robotics, electric drives, process control, vehicle and motion control [20].

Sliding mode control consists of three parts: a sliding surface, switching control and equivalent control. The sliding surface is the desired state trajectories. Switching control is a discontinuous control law to drive a system state to converge to the surface. Equivalent control is a continuous control law to force the state to remain on the surface [21].

The purpose of sliding mode control is to drive the plant trajectory to a sliding surface and to maintain the 
trajectory on the sliding surface in subsequent time. So the first step of designing a sliding mode controller is to select a sliding surface. When a system's trajectory is above the surface, the feedback controller has one gain. When the trajectory is below the surface, the feedback controller has another gain. Consider a nonlinear system which can be defined as Eq. (7):

$$
x^{(n)}=f\left(x, \dot{x}, \ddot{x}, \dddot{x}, x^{(n-1)}, t\right)+b(x, t) u(t)
$$

In Eq. (7), $x(t)$ is the state vector; $n$ indicates the highest order of the system; $f(x, t)$ and $b(x, t)$ are nonlinear functions of time and state; and $u(t)$ is the control input. The sliding surface is defined as:

$$
s(x, t)=\left(\frac{d}{\mathrm{~d} t}+\delta\right)^{(n-1)} \tilde{x}(t)
$$

where, $\delta$ is a strict positive constant; and $\tilde{x}(t)$ is the error between the output state $x(t)$ and desired output .

For a second order system, the sliding surface will be $s=\dot{e}+c e$ and its demonstration in phase plane is presented in Fig. 2. In Fig. 2, SMC (sliding mode control) should force any initial states to land on the sliding surface in a finite time. If both the tracking error and the derivative of the tracking error are zero, the system states reach the demanded states [21].

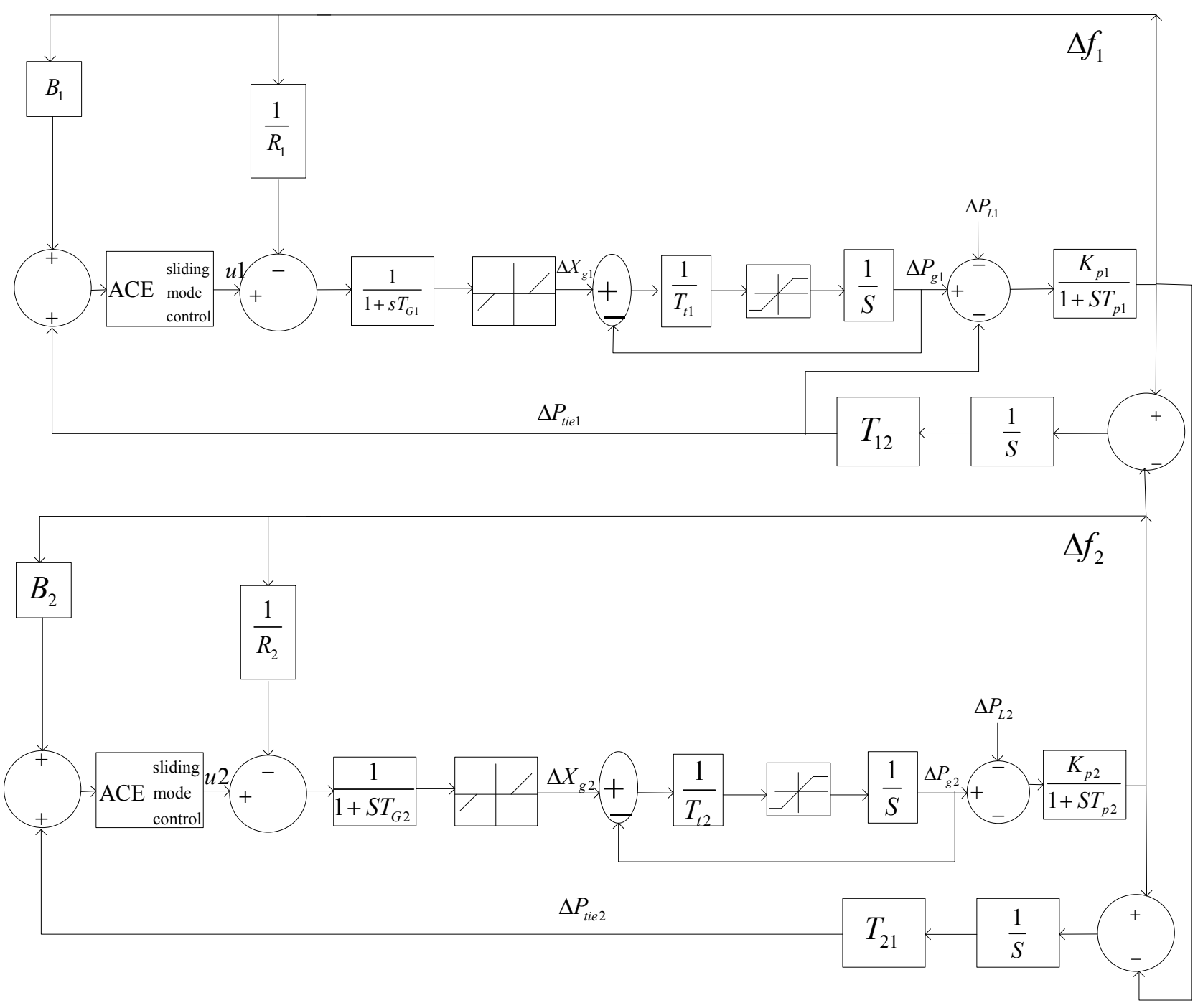

Fig. 1 The block diagram of two areas thermal power system with nonlinearities. 


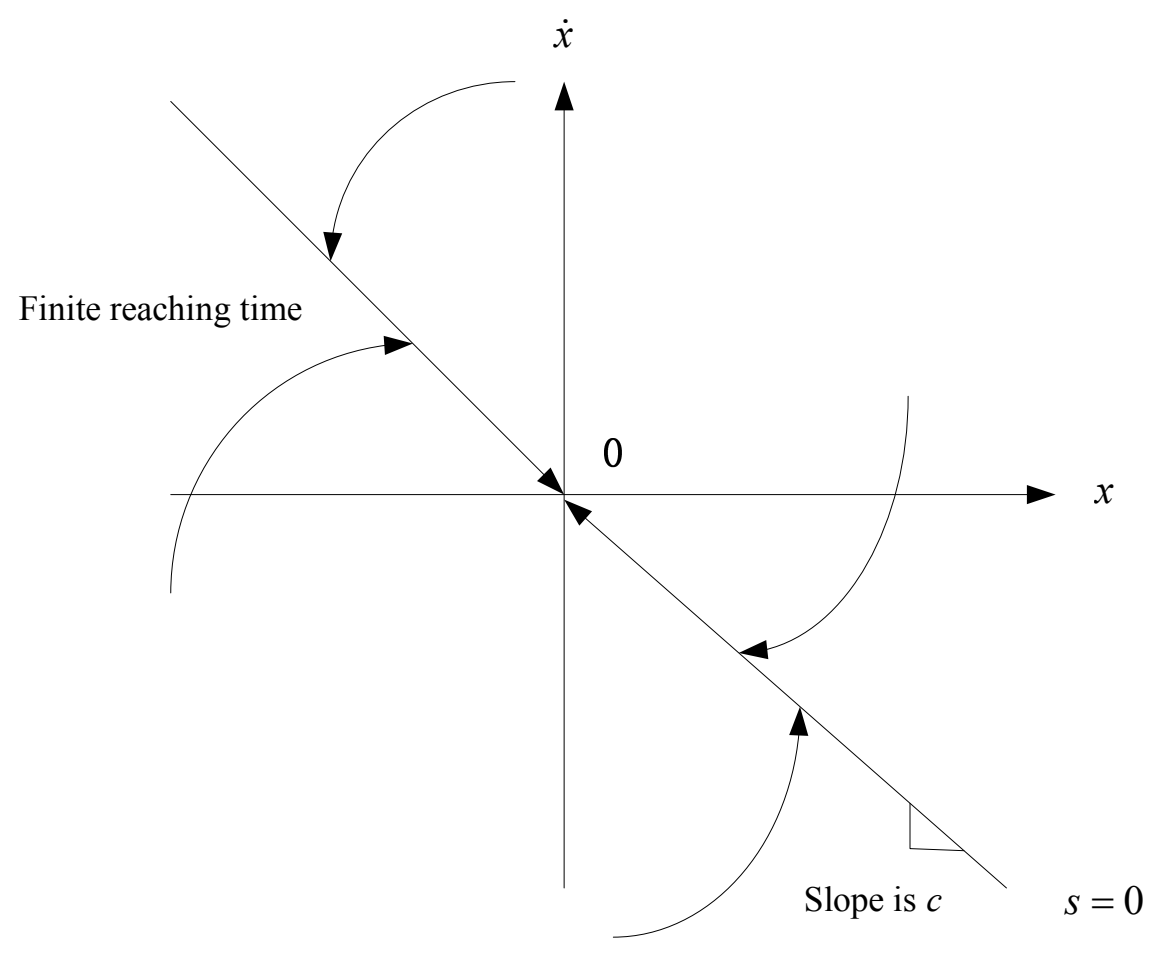

Fig. 2 Sliding surface.

After the sliding surface is defined, the switch control law is used to force the system states to land on the sliding surface even if there is a disturbance. The switching law can be defined as Eq. (9), where, $u$ is switching control law; $u_{0}$ is the positive control gain; and $s$ is the sliding surface. The switching law has two outputs depending on the sign of sliding surface. If the sliding surface is positive, the switching control law is positive and vice versa [21].

$$
u=u_{0} \operatorname{sgn}(s)
$$

The equivalent control is used to keep the system states stay on the sliding surface. Equivalent control law is used to compensate system uncertainties [21]. The sliding mode control is designed as follows.

We consider a second order system as:

$$
\ddot{x}(t)=f(x, t)+b(x, t) u(t)
$$

The sliding surface is defined as:

$$
s(x, t)=\left(\frac{d}{\mathrm{~d} t}+\delta\right) \tilde{x}(t)=\dot{\tilde{x}}(t)+\delta \tilde{x}(t)
$$

Differentiation the sliding surface yields:

$$
\dot{s}(x, t)=\ddot{x}(t)-\ddot{x}_{d}(t)+\delta \dot{\tilde{x}}(t)
$$

Substituting Eq. (10) into Eq. (12), we have:

$$
\dot{s}(x, t)=f(x, t)+b(x, t) u(t)-\ddot{x}_{d}(t)+\delta \dot{\tilde{x}}(t)
$$

where, $\quad b(x, t)$ is bounded as $0 \leq b_{\min }(x, t) \leq b(x, t) \leq b_{\max }(x, t)$. Then, the estimate of $b(x, t)$ which is represented by $\hat{b}(x, t)$ is given by $\hat{b}(x, t)=\sqrt{b_{\min }(x, t) b_{\text {max }}(x, t)}$. We suppose the estimated $f(x, t)$ is $\hat{f}(x, t)$.

From Eq. (14), if we choose the approximate control law $\hat{u}(t)$ as:

$$
\hat{u}(t)=-\frac{1}{\hat{b}(x, t)}\left[\hat{f}(x, t)-\ddot{x}_{d}(t)+\delta \dot{\tilde{x}}(t)\right]
$$

and replace $u(t)$ in Eq. (13) with the $\hat{u}(t)$ in Eq. (14), we will make $\dot{s}(x, t)=0$. In order to account for the uncertainty in $f$ and to satisfy the sliding condition, Eq. (15) is defined as follows, where $\eta$ is positive.

$$
\frac{1}{2} \frac{d}{\mathrm{~d} t}\left(s(t)^{2}\right) \leq-\eta|s(t)|
$$

Take the real control law as:

$$
u(t)=\hat{u}(t)-k(x, t) \operatorname{sgn}(s(t))
$$


where, $k(x, t)>0$ and if $k(x, t)$ is chosen large enough, Eq. (16) will be satisfied.

\section{Control Solution}

For the non-reheat turbine, according to the sliding mode control law, we firstly set $x=\Delta f$. Then we can get the third order of the frequency error.

$$
\begin{aligned}
\dddot{x}= & \left(u-\frac{1}{R} x\right) \frac{k_{p}}{T_{H} T_{t} T_{P}}-\frac{k_{p}}{T_{t} T_{P}} \Delta \dot{P}_{L} \\
& -\frac{1}{T_{t}} \ddot{x}-\frac{1}{T_{t} T_{P}} \dot{x}-\frac{k_{p}}{T_{P}} \Delta \ddot{P}_{L}-\frac{1}{T_{P}} \ddot{x} \\
& -\frac{k_{p}}{T_{H} T_{t} T_{P}} \Delta P_{L}-\frac{1}{T_{H} T_{t}} \dot{x}-\frac{1}{T_{H} T_{t} T_{P}} x \\
& -\frac{k_{p}}{T_{H} T_{P}} \Delta-\frac{1}{T_{H}} \ddot{x}-\frac{1}{T_{H} T_{P}} \dot{x}
\end{aligned}
$$

The sliding surface is designed as:

$$
\begin{aligned}
s(x, t) & =\left(\frac{d}{\mathrm{~d} t}+\delta\right)^{2} \tilde{x}(t) \\
& =\ddot{x}(t)+2 \delta \dot{x}(t)+\delta^{2} x(t)
\end{aligned}
$$

In Eq. (18), $\tilde{x}(t)=x(t)-0=x(t)$.

The derivative of sliding surface is in Eq. (19):

$$
\dot{s}(x, t)=\dddot{x}(t)+2 \delta \ddot{x}(t)+\delta^{2} \dot{x}(t)
$$

Let the derivative of sliding surface is equal to zero, the approximate control law can be derived as shown in Eq. (20):

$$
\begin{aligned}
\hat{u}(t)= & \frac{1}{R} x+T_{H} \Delta \dot{P}_{L}+\frac{T_{H} T_{P}}{k_{p}} \ddot{x} \\
& +\frac{T_{H}}{k_{p}} \dot{x}+T_{H} T_{t} \Delta \ddot{P}_{L}+\frac{T_{H} T_{t}}{k_{p}} \ddot{x} \\
& +\Delta P_{L}+\frac{T_{P}}{k_{p}} \dot{x}+\frac{1}{k_{p}} x+T_{t} \Delta \dot{P}_{L} \\
& +\frac{T_{t} T_{P}}{k_{p}} \ddot{x}+\frac{T_{t}}{k_{p}} \dot{x} \\
& -\left[2 \delta \ddot{x}(t)+\delta^{2} \dot{x}(t)\right] \frac{T_{H} T_{t} T_{P}}{k_{p}}
\end{aligned}
$$

The control law can be selected as:

$$
u=\hat{u}(t)-k \operatorname{sgn} s(x, t)
$$

\section{Simulation Results}

Firstly, the load disturbance is set 0.01 p.u. at $t=2 \mathrm{~s}$ in Area 1 and the load disturbance is set to
0.01 p.u. around $t=4 \mathrm{~s}$ in Area 2. This is the first case and the simulation results are shown in Figs. 3-8. From Figs. 3-8, it can be concluded that, the frequency error, tie-line power error and area control error can be driven to zero in both areas.

The load disturbance is set to 0.02 p.u. around $t=2 \mathrm{~s}$ in Area 1 and the load disturbance is set to 0.03 p.u. at $t=4 \mathrm{~s}$ in Area 2, which is the case 2. The load disturbance is set to 0.08 p.u. around $t=2 \mathrm{~s}$ in Area 1 and the load disturbance is set to 0.1 p.u. at $t=4 \mathrm{~s}$ in Area 2, which is case 3. Figs. 9-14 compare the waveform under cases 2 and 3. From Figs. 9-14, we can conclude that, the frequency errors, tie-line power errors and area control errors can be driven to

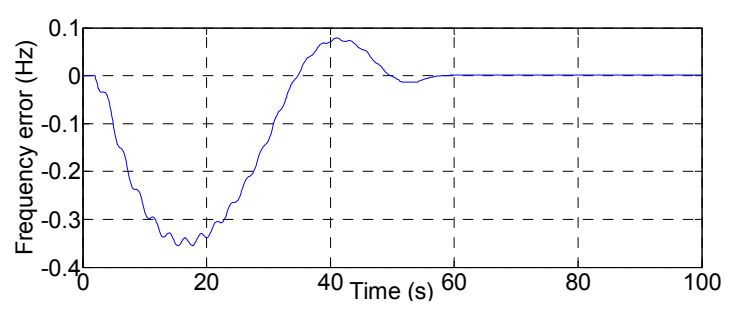

Fig. 3 Frequency error in Area 1 under case 1.

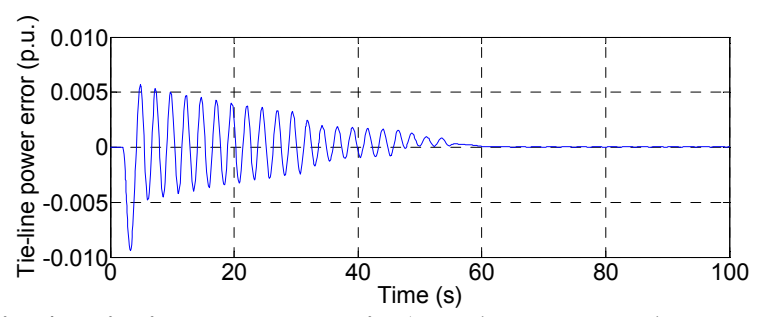

Fig. 4 Tie-line power error in Area 1 under case 1.

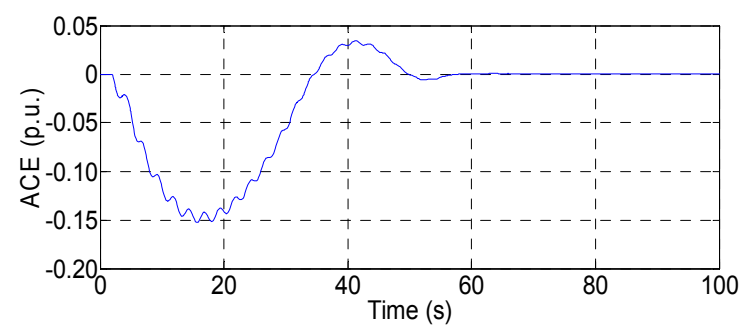

Fig. 5 Area control error in Area 1 under case 1.

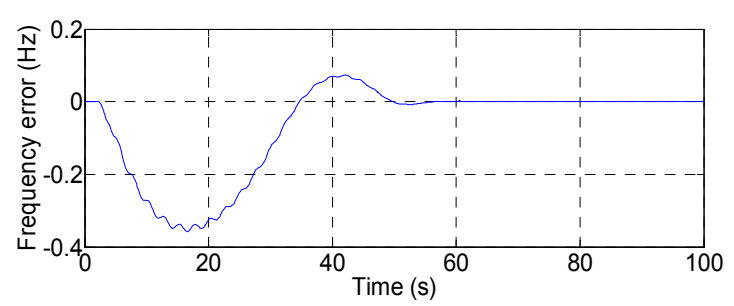

Fig. 6 Frequency error in Area 2 under case 1. 


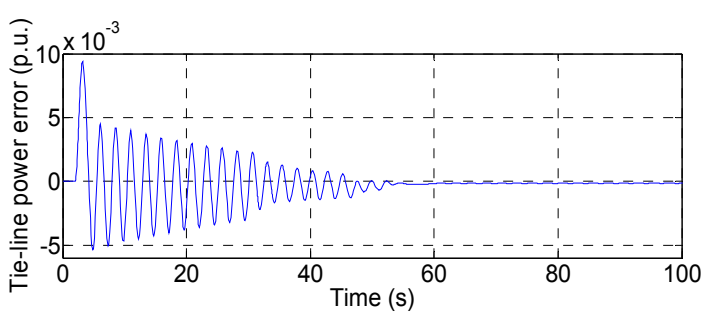

Fig. 7 Tie-line power error in Area 2 under case 1.

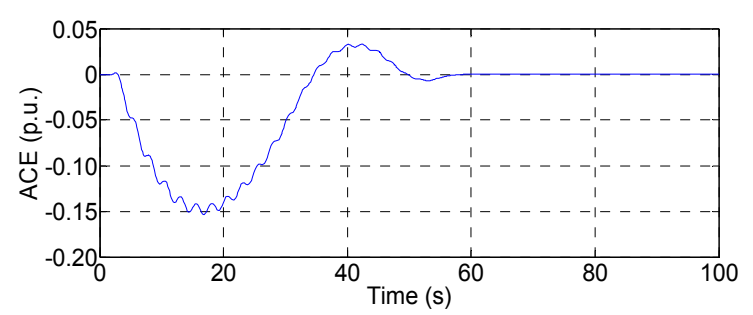

Fig. 8 Area control error in Area 2 under case 1.

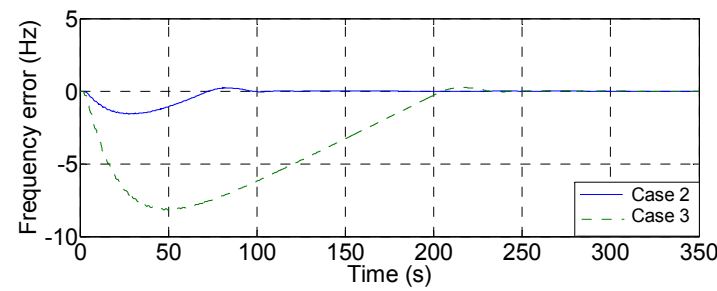

Fig. 9 Frequency errors in Area 1 under cases 2 and 3.

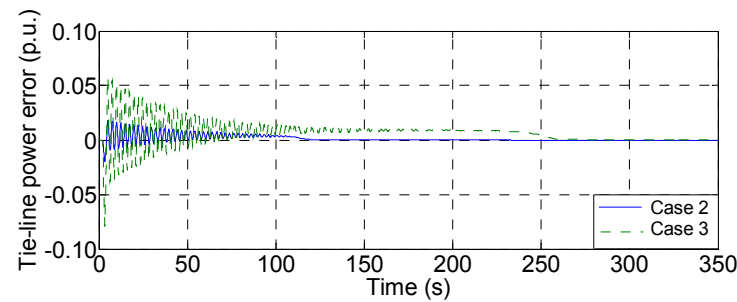

Fig. 10 Tie-line power errors in Area 1 under cases 2 and 3.

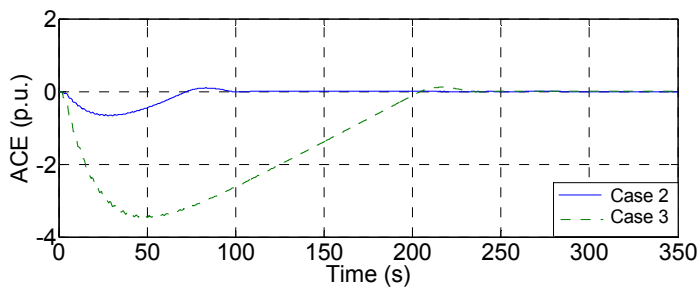

Fig. 11 Area control errors in Area 1 under cases 2 and 3.

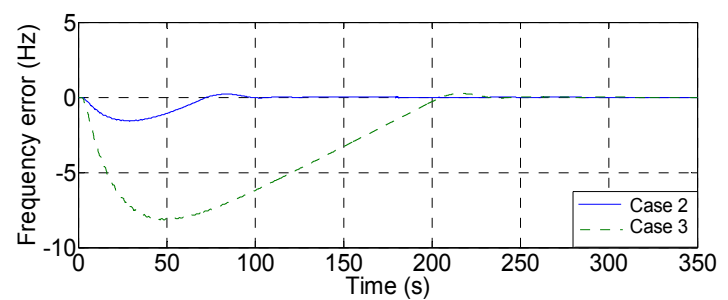

Fig. 12 Frequency errors in Area 2 under cases 2 and 3.

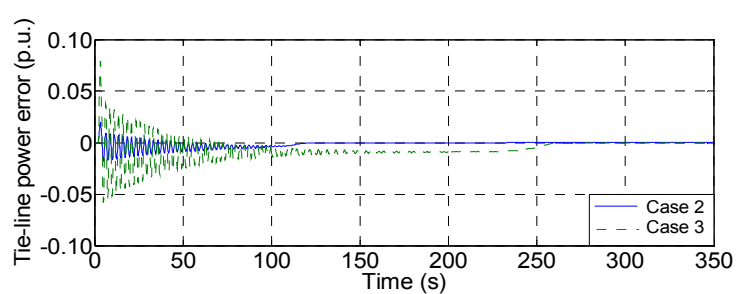

Fig. 13 Tie-line power errors in Area 2 under cases 2 case 3.

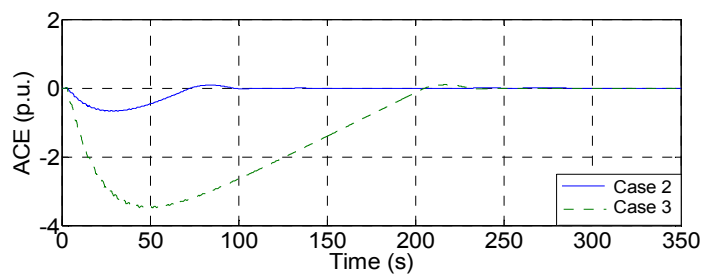

Fig. 14 Area control errors in Area 2 under cases 2 and 3.

zero under different cases. If the load disturbance becomes larger, the overshoot is higher and the settling time becomes longer.

In order to test the robust of the control method, the parameters change above and below $20 \%$ of the nominal values. Figs. 15-20 show the waveform for the three different situations. The load disturbance is set to 0.01 p.u. around $t=2 \mathrm{~s}$ and the load disturbance is set to 0.02 p.u. around $t=4 \mathrm{~s}$. From Figs. $15-20$, it is verified that, we can get the desired result through the proposed control method. The frequency errors, tie-line power errors, and area control errors can be regulated to zero under the parameters variation.

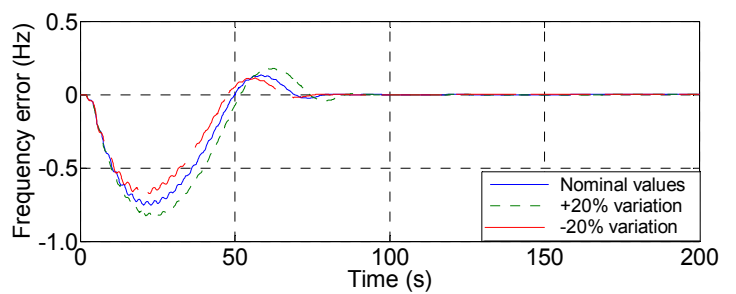

Fig. 15 Frequency errors in Area 1 under nominal value and parameters change.

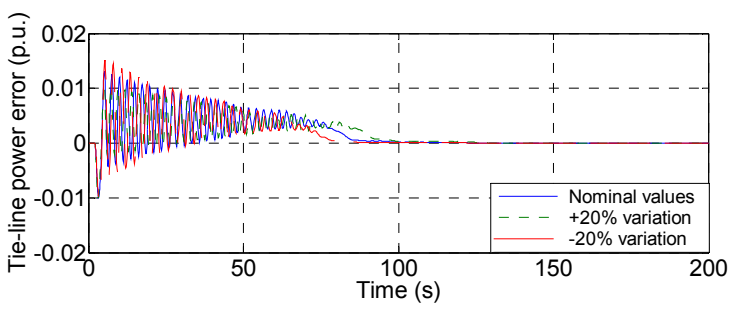

Fig. 16 Tie-line power errors in Area 1 under nominal value and parameters change. 


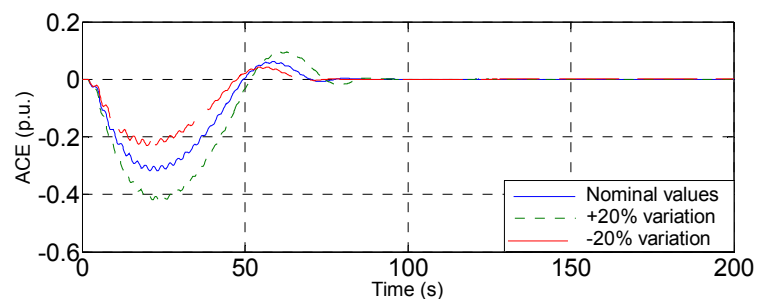

Fig. 17 Area control errors in Area 1 under nominal value and parameters change.

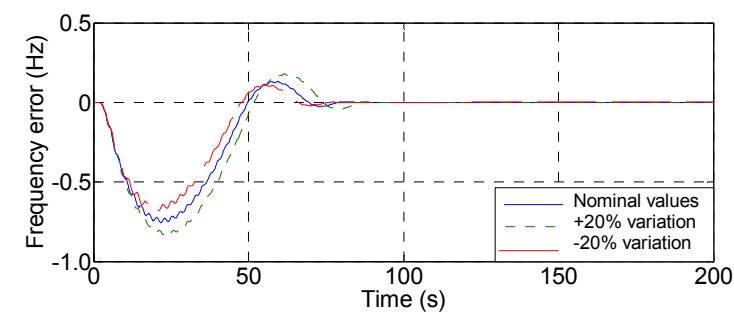

Fig. 18 Frequency errors in Area 2 under nominal value and parameters change.

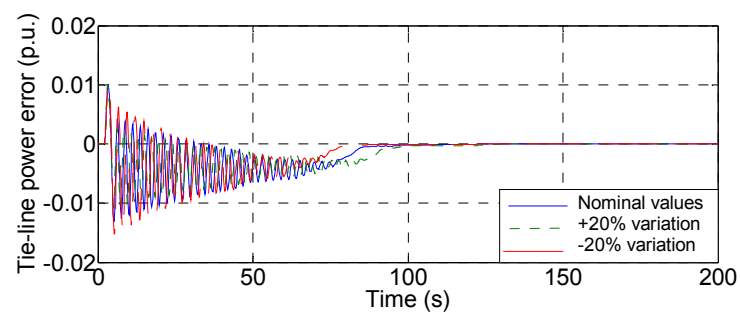

Fig. 19 Tie-line power errors in Area 2 under nominal value and parameters change.

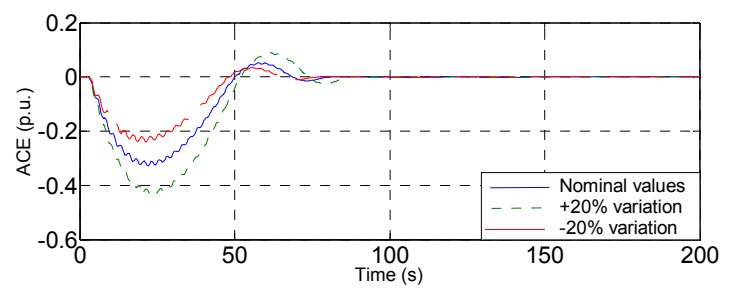

Fig. 20 Area control errors in Area 2 under nominal value and parameters change.

In order to illustrate the robustness of the proposed control method in a multi-area power system, consider the three area identical interconnected power systems with non-reheat turbines as shown in Fig. 21 [22]. The system is tested in a load disturbance of 0.01 p.u. at $t=2 \mathrm{~s}$ in Area 1, load disturbance of 0.03 p.u. around $t=6 \mathrm{~s}$ in Area 2, and load disturbance of 0.02 p.u. around $t=3 \mathrm{~s}$. Figs. 22-24 depict the frequency errors, tie-line power errors, and area control errors for the three areas. Even in this condition, the system can still keep stable with SMC scheme.

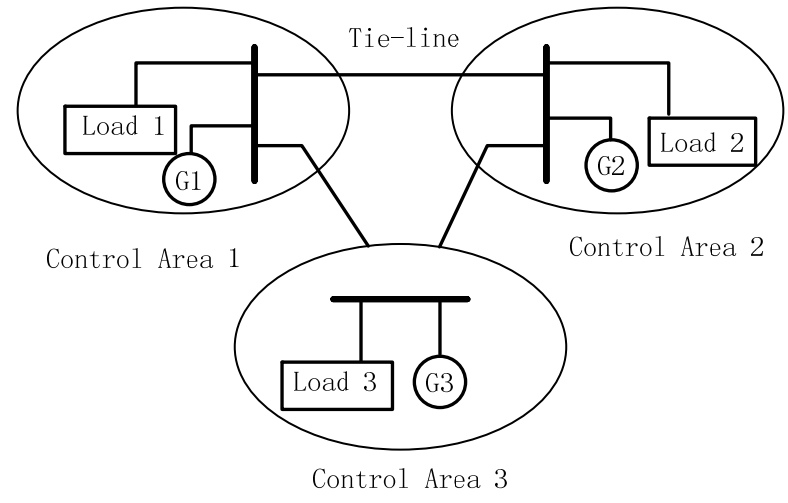

Fig. 21 Three control-area power system.

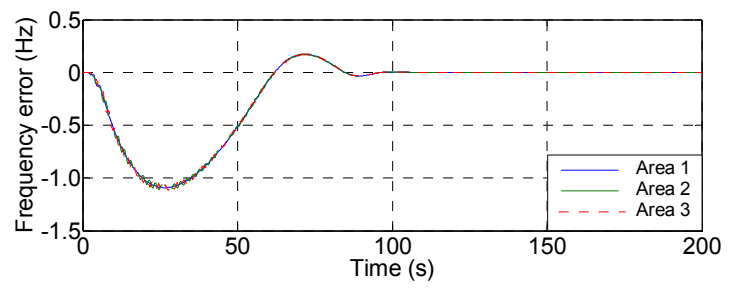

Fig. 22 Frequency errors in three areas for the interconnected power system.

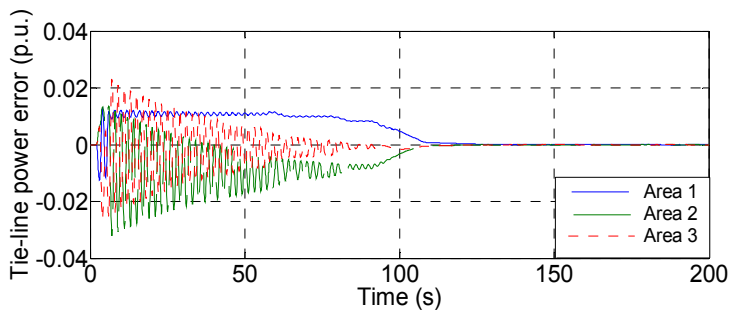

Fig. 23 Tie-line power errors in three areas for the interconnected power system.

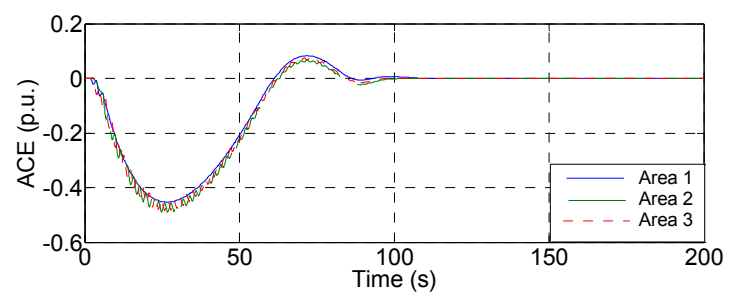

Fig. 24 Area control errors in three areas for the interconnected power system.

\section{Concluding Remarks}

This study is an application of SMC to an interconnected nonlinear power system. The nonlinearities of the power system include governor dead band and GRC (generation rate constraint). The proposed scheme has applied to two areas and three areas power system with non-reheat turbines in the presence of parameters variation and different load 
disturbances. The simulations have been carried out in order to test the effectiveness of the proposed control strategy. Through the simulation results, it is verified that, the proposed control method demonstrated good robustness in the face of several parameters change and different load disturbances.

\section{References}

[1] Shayeghi, H., Shayanfar, H., and Jalili, A. 2009. "Load Frequency Stratigies: a State of the Art Survey for the Researcher." Energy Conversion and Management 50 (2): 344-53.

[2] RerkPreedapong, D., Hasanovic, A., and Feliachi, A. 2003. "Robust Load Frequency Control Using Genetic Algorithms and Linear Matrix Inequalities." IEEE Transactions on Power Systems 18 (2): 855-61.

[3] Cam, E. 2007. "Application of Fuzzy Logic for Load Frequency Control of Hydro-Electrical Power Plants." Energy Conversion and Management 48 (4): 1281-8.

[4] Juang, C., and Lu, C. 2004. "Power System Load Frequency Control by Evolutionary Fuzzy PI Controller." In Proceedings of the IEEE International Conference on Fuzzy System, 715-9.

[5] Juang, C., and Lu, C. 2006. "Load Frequency Control by Hybrid Evolutionary Fuzzy PI Controller." IEE Proceedings of Generation, Distribution, and Transmission 153 (2): 196-204.

[6] Mohamed, T., Bevrani, H., Hassan, A., and Hiyama, T. "Model Predictive based Load Frequency Control Design," In Proceedings of the 16th International Conference of Electrical Engineering, 1-6.

[7] Rerkpreedapong, D., Atic, N., and Feliachi, A. 2003. "Economy Oriented Model Predictive Load Frequency Control." In Proceedings of the 2003 Large Engineering Systems Conference on Power Engineering, 12-6.

[8] Venkat, A., Hiskens, I., Rawlings, J., and Wright, S. 2008. "Distributed MPC Strategies with Application to Power System Automatic Generation Control." IEEE Transactions on Control System Technology 16 (6): 1192-206.

[9] Mohamed, T., Bevrani, H., Hassan, A., and Hiyama, T. 2011. "Decentralized Model Predictive based Load Frequency Control in an Interconnected Power System." Energy Conversion and Management 52 (2): 1208-14.

[10] Glover, J., and Schweppa, F. 1972. "Advanced Load
Frequency Control." IEEE Transactions on Power Apparatus and System 91 (5): 2095-103.

[11] Bengiamin, N., and Chan, W. 1978. "Multilevel Load-Frequency of Interconnected Power Systems." Institutions of Electrical Engineers 125 (6): 521-6.

[12] Chan, W., and Hsu, Y. 1981. "Automatic Generation Control of Interconnected Power System Using Variable Structure Controllers." IEE Proceedings of Generation, Transmission, and Distribution 128 (5): 269-79.

[13] Al-Hamouz, Z., Al-Musabi, N., and Al-Duwaish, H. 2007. "A Tabu Search Approach for the Design of Variable Structure Load Frequency Controller Incorporating Nonlinearities." Journal of Electrical Engineering 58 (5): 264-70.

[14] Vrdoljak, K., Peric, N., and Petrovic, I. 2010. "Sliding Mode based Load-Frequency Control in Power Systems." Electric Power Systems Research 80 (5): 514-27.

[15] Yang, M., Fu, Y., Wang, C., and Wang, P. 2013. "Decentralized Sliding Mode Load Frequency Control for Multi-area Power System." IEEE Transactions on Power System 28 (4): 4301-9.

[16] Yang, M., and Lu, H. 1999. "Sliding Mode Load-Frequency Controller Design for Dynamic Stability Enhancement of Large-Scale Interconnected Power Systems." In Proceedings of the IEEE International Symposium on Industrial Electronics, 1316-21.

[17] Ding, X., and Sinha, A. 2011. "Sliding Mode/ $H \infty$ Control of Hydro-Power Plant." In Proceedings of the 2011 American Control Conference, 5201-6.

[18] Hanley, M. 2011. "Frequency Instabilities in North America Interconnections.” National Energy Technology Laboratory.

[19] North American Electric Corporation. 2012. "Frequency Response Initiative Report." North American Electric Corporation.

[20] Sabanovic, A., Fridman, L., and Spurgeon, S. 2004. "Variable Structure Systems: From Principles to Implementation." In IEE Control Engineering, London: The Institution of Engineering \& Technology.

[21] Zhao, Y. 2012. "Applications of Sliding Mode Controller and Linear Active Disturbance Rejection Controller to a PMSM Speed System.” M.S. thesis, Cleveland State University.

[22] Mohamed, T., Bevrani, H., Hassan, A., and Hiyama, T. 2010. "Decentralized Model Predictive based Load Frequency Control in an Interconnected Power System." Energy Conversion and Management 52 (2): 1208-14. 